Departamento de Historia

Universidad de Santiago de Chile

Revista de Historia Social

y de las Mentalidades

Volumen 24, N², 2020: 213-232

Issn Online: 0719-4749

\title{
ACCESO A ARCHIVOS PERSONALES, UN APORTE A LA HISTORIA RECIENTE: EL CASO DEL ARCHIVO JAIME GUZMÁN*
}

\author{
ACCESS TO PERSONAL ARCHIVES, A CONTRIBUTION TO CONTEMPORARY HISTORY: \\ THE CASE OF JAIME GUZMÁN'S ARCHIVE
}

\author{
LIC. BENJAMÍN COFRÉ** \\ Fundación Jaime Guzmán \\ Santiago, Chile \\ Email: benjamin.cofre@usach.cl \\ Id-ORCID: 0000-0002-1904-8405
}

\begin{abstract}
RESUMEN
La archivística se desarrolla en espacios de alcances amplios, como los archivos nacionales, pero también a escalas menores, pasando desde las grandes instituciones, las familias y, cómo no, las personas y sus archivos privados. Este trabajo propone una revisión teórica sobre los archivos personales y su uso historiográfico como fuente para la interpretación de la historia de Chile, con especial interés en la historia reciente del país. El artículo se desarrolla desde la definición de estos archivos, su relación con la historia, además de los desafíos de acceso a sus fondos documentales y el rol que los archiveros desempeñan en estos espacios, proponiendo como caso de estudio el Archivo Jaime Guzmán, persona de controversial interés para la historia chilena.

Palabras clave: Archivos personales; Historia reciente; acceso; Archivo Jaime Guzmán
\end{abstract}

\begin{abstract}
The Archival Science develops in ample spaces, as the national archives, but also in minor scales, going through big institutions, families, and not least, individuals and their private archives. This work proposes a theoretical revision of personal archives and its historiographic use as a source for the interpretation of Chilean History, with special interest in the contemporary History of the country. The article addresses the definition of this archives, its relation with History, also the access problems to its documentary collections and the role that archivists develop in these spaces, proposing as a case of study the Jaime Guzman's Archive, a controversial person of interest to the chilean history.
\end{abstract}

Keywords: Personal Archives; Contemporary History; Access; Jaime Guzman's Archive

* $\quad$ Recibido: 28 de febrero de 2020; Aprobado: 28 de abril de 2020.

** Artículo científico. Investigación personal. Realizado como conclusión de trabajos presentados en el desarrollo del Diploma de Postítulo en Archivística 2019 del Archivo Nacional junto con la Universidad de Chile. 
Cómo citar: Cofré, Benjamín. (2020). "Acceso a archivos personales, un aporte a la Historia reciente: El caso del archivo Jaime Guzmán”. Revista Historia Social y de las Mentalidades, 24(2), 213-232. DOI: 10.35588/rhsm.v24i2.4374

\section{INTRODUCCIÓN}

No creo que los seres humanos se movilicen en mera función de recuerdos. Pero pienso que tampoco puede impulsarse fecundamente la voluntad creadora de los pueblos, de espaldas a su pasado o sin arraigo en su propia historia.

"Dos 11 de septiembre históricos", La Segunda (1982)

Jaime Guzmán

Al observar el pasado desde la vasta expresión bibliográfica de la disciplina de la historiografía, se puede comprender que no es una lista de títulos agotada, y que mucho queda todavía por conocer, escribir y reflexionar $-\mathrm{y}$ aun lo que ya se ha escrito puede cuestionarse, tensionarse o revisitarse en un estudio-. Lo anterior se debe a que la reconstrucción de este pretérito requiere de la agencia historiográfica, de un historiador (Collingwood 66), a partir de vestigios fragmentados que dan cuenta de que algo ocurrió. Dicho de otro modo, únicamente contamos con parte de esa información aislada e incompleta y, por lo mismo, el pasado siempre será "inevitablemente incierto, discontinuo, lagunoso: basado sobre una masa de fragmentos y ruinas" (Ginzburg 54). Sin embargo, el historiador busca en el pasado hechos a los cuales dota de importancia de manera tal que pueda ser relevado a un estatus de "histórico" (Carr 81-82), para lo cual, debe generar una narrativa que permita unir los fragmentos de pasado, representada en información parcelada que se extrae de fuentes, entregándole un cuerpo sólido y coherente, proveyéndolo de las pruebas que transforman el relato en algo verosímil, conformándose así lo que conocemos como Historia (López 161; ${ }^{1}$ White 182). Por ello, al reconocer un pasado incompleto, es necesario recurrir a las pruebas primigenias -las fuentes primarias-, que permiten comprender dicho tiempo sin la mediación de la narrativa de un historiador, aun cuando sí se encuentre mediada por las del productor.

1 Lo que López refiere como los dos dificultosos esfuerzos paralelos que realizan los historiadores: el enlazar una narrativa interesante que logre reconstruir una parte del pasado, pero con el trabajo cuidadoso y directo de las fuentes y la bibliografía consultada. 
Para este trabajo, el rol de fuente lo ocupará el "documento de archivo", que es aquella documentación que, independiente de su soporte, permite dar cuenta del proceso del actuar de una persona o institución y, como señala Cruz Mundet, que "como resultado de ese devenir, constituyen la base para la elaboración de la historia" (Administración 18).

Roberto Pittaluga, historiador argentino, recuerda al filósofo francés Paul Ricœur para añadir que un documento "no es dado sino buscado, encontrado, fabricado; es el resultado de un resto que es recortado, circunscripto, constituido en documento", siendo lo anterior parte del proceso mismo de la construcción historiográfica "en el cual se anudan las huellas y los documentos -los dos polos de dicho proceso- con las preguntas del historiador". Aclara el historiador que, previo a que la pregunta de investigación que da origen a un estudio sea respondida, existe el momento del archivo, práctica que diseña el espacio, el lugar, de producción de la disciplina de la historia: "Lugar físico y lugar social, decía de Certeau (sic), pues la institución historiadora - de la cual el archivo es parte central- construye las fuentes a través de ciertos parámetros, en una concatenación de operaciones veritativas que hacen de la huella una prueba documental para uso historiográfico" (Pittaluga 203).

Los documentos de archivo, por su propia función y composición, tienen un carácter probatorio que, para los historiadores, se traduce en que esas fuentes sostienen las reconstrucciones del pasado como la estructura que entrega la realidad a la historia que le es inherente.

Este necesario andamiaje se torna problemático a la hora de estudiar la historia reciente de Chile, período que sigue siendo controversial, socialmente vivo, ya que "Toda la Historia se ha convertido en uno de esos temas delicados, una de esas preguntas vivas de la enseñanza [...]" (Falaize 197). ${ }^{2}$ En otros términos, no existe hoy una postura unánime respecto del proceso sociohistórico vivido desde el Gobierno de la Unidad Popular en adelante: el gobierno de Salvador Allende (1970-1973), el Régimen Militar de Augusto Pinochet (19731990), y los posteriores mandatos contemporáneos o "transicionales" (desde 1990). Razón por la cual el estudio y literatura escritos sobre este lapso es hoy abundante, tratando de explicar la situación actual del país en las instituciones generadas durante todo el período anteriormente mencionado.

A esta dificultad teórica por lo controversial, debe sumársele el reconocimiento de la historiografía como campo de disputa político e ideológico para el caso chileno a partir del 11 de septiembre de 1973, y que, desde el 
período finisecular, ha transcurrido "en medio de una suerte de crisis existencial disciplinaria, interpelada adicionalmente por los profundos cuestionamientos epistemológicos emanados del debate internacional" (Pinto 16). Desde la tensión anterior, aparece otro desafío insoslayable: la consecución de las fuentes para el estudio histórico, considerando el cuestionamiento de las nuevas perspectivas disciplinares al registro que ofrecen los medios de comunicación, ${ }^{3}$ así como de las cifras oficiales del Gobierno. En definitiva, se requiere de nuevos insumos, nuevas fuentes, que posibiliten revisitar las investigaciones de nuestro pasado reciente. Este último punto permite valorizar el alcance que puede tener en las investigaciones sobre la historia contemporánea los archivos especiales, como lo son los archivos personales, que se distancian de las concepciones monumentales de la identidad nacional -y, por ello, de los archivos nacionales-, conformándose únicamente por el quehacer de una persona en particular.

Sobre este respecto, cabe mencionar que dentro de los archivos nacionales, y particularmente el caso chileno, sí existen fondos personales como parte de la institución mayor, pero responden, principalmente, a personas de interés público por el mandato del DFL 5200 que crea el Archivo Nacional de Chile y que, en su artículo 13, menciona que: "tiene por objeto reunir y conservar los archivos de los departamentos de Estado y de todos los documentos y manuscritos relativos a la historia nacional, y atender a su ordenación y aprovechamiento", y que, en el artículo 15, además agrega que "la Dirección General adquirirá todos aquellos documentos, impresos y objetos que se encuentren en poder de particulares y que tengan interés para la historia patria y para las colecciones de los establecimientos a su cargo". Podemos concluir entonces que, comprende los fondos personales en tanto aporte a la historia nacional, y no en su individualidad como personas más allá de su quehacer público - no obstante que esta perspectiva pudo empezar a abrirse hacia nuevos intereses propios de los cambios de paradigmas tanto archivísticos como historiográficos y, por qué no, sociales-.

Si se considera que, además, la propia disciplina archivística aún debate respecto de los archivos personales, no solo si estos se consideran o no archivos, ${ }^{4}$ a otros autores- referido al rol, por ejemplo, en posicionar el liberalismo económico como un horizonte para Chile (7).

4 Hay autores que plantean que los archivos personales en realidad son colecciones (Bossié 1), pero al contener documentación única producida en la realización de una actividad realizada periódicamente y que evidencian acciones, decisiones y funciones propia de la persona, cumple con las condiciones que los archivos institucionales o nacionales al guarecer documentos de archivo vinculados a sí mismos (Cruz Mundet, Diccionario 78 y 146). 
sino que además respecto del papel que sus encargados, los archiveros, desempeñan dentro del quehacer disciplinar:

Casi todos los clásicos libros de metodología archivística fueron escritos pormiembros destacados delosarchivosnacionalesenEuropa. No nos sorprende pues que la mayoría de estos libros se centraran en los documentos gubernamentales, públicos o institucionales y en su transferencia ordenada a depósitos archivísticos para preservar su orden y clasificación originales; y que la mayoría de los archivos privados y personales, fueran relegados al ámbito de las bibliotecas y de los bibliotecarios. ¿Por qué -podríamos preguntarnos- los archivos personales (y archiveros) no forman parte de los archivos nacionales en la mayoría de los países? ¿Por qué se llama archiveros a aquellos que en los archivos se encargan de los documentos del gobierno y a aquellos que se ocupan de los documentos personales en las bibliotecas se les llama conservadores de manuscritos o bibliotecarios especiales, con todo el conjunto de connotaciones y suposiciones relacionadas con cada término? [...] Estas divisiones históricas fundamentales dentro de la organización interna de la memoria archivística, dentro de los archivos entre público y privado [...] no es más que una prueba cruel de que el esfuerzo archivístico, tal como lo formularon, practicaron y codificaron los pioneros, no estaba tan libre de valores como creían (Cook 159).

El Archivo Jaime Guzmán (AFJG) es una institución dependiente de la fundación dedicada al exsenador Jaime Guzmán Errázuriz y que cuenta con 160 $\mathrm{m}$ lineales de capacidad, con $110 \mathrm{~m}$ lineales ocupados con dos fondos: el Fondo Jaime Guzmán (cerrado), que contempla la obra escrita y recuperada por Jaime Guzmán en vida, y el Fondo FJG (abierto), que contiene la producción de la Fundación como organización. Para efectos de este texto, cuando se hable sobre el Archivo Jaime Guzmán, se considera únicamente el fondo personal.

Para el presente escrito, se revisa Archivo de Guzmán como una fuente que permita comprender el proceso político vivido por el país desde la segunda mitad del siglo XX, de la mano de quien "Ha sido reconocido como una de las figuras más relevantes de la historia política reciente de Chile. Se trata del colaborador civil más importante del régimen militar y probablemente es el personaje más decisivo en la definición del camino político e ideológico asumido por la Junta Militar tras el golpe de Estado de septiembre de 1973" (Castro, Jaime Guzmán, ideas y política 11). Así, por su 
participación [...] durante el gobierno militar, genera controversia y crítica en temas como las violaciones a los derechos humanos, la democracia y la Constitución de 1980. Sectores antagónicos lo apuntan como el gran responsable de las trabas legales para cambiar la carta principal de Chile, y los más acérrimos contrincantes explican su muerte como un destino inevitable por la confrontación que se atrevió a dar contra los grupos violentos que tuvieron su auge durante el régimen militar, período en que Guzmán fue actor relevante.

Con todo, siempre llamó la atención, para bien o para mal, a seguidores y detractores. Para los primeros fue un hombre de vida ejemplar que se convirtió en su máximo líder. Para los segundos fue una persona de extremos que, aunque respetado y considerado, siempre fue visto como una amenaza. (Mayol et al. 7)

El cometido del presente artículo es la revisión por parte de la disciplina archivística de los aportes de los archivos personales a la labor historiográfica, siendo el caso presentado solo una muestra de una institución de las características descritas - privado, personal y de interés ciudadano e histórico, al tratarse su productor de un protagonista de nuestra controvertida historia reciente-. Este análisis radica en el contenido del fondo documental, el acceso a este acervo, así como la importancia de la disposición de su contenido en materias que son de interés hoy para la discusión pública y, por lo mismo, los alcances en el conocimiento de la historia reciente que puede tener un archivo personal de estas características, pues

Si bien el trabajo archivístico ha inclinado la balanza hacia el estudio de los archivos institucionales más que hacia los personales, estos últimos tienen una gran importancia para la reestructuración histórica de hechos significativos, porque es en ellos donde se encuentran las ideas, posiciones y percepciones de personalidades con actuaciones relevantes en la historia (Rosell León).

En definitiva, esta intromisión a las piezas documentales de aquel hombre sindicado como protagonista es un imperativo a la hora de comprender la relación entre su pensar y su hacer y como el contexto de producción influye y es influenciado. Cabe aclarar que este trabajo no busca aportar a los escritos sobre la vida y obra de Jaime Guzmán, y es por ello que no se realiza una investigación más completa sobre la biografía del exsenador. Por el contrario, lo que pretenden 
estas líneas es demostrar que, como toda obra, el contexto de producción de los escritos del líder gremialista debe considerarse para entender, en una visión más bien global, que "La comprensión de la dinámica de las continuidades y los cambios de la evolución de las ideas políticas de Jaime Guzmán permite comprender el significado que ellas tuvieron cuando fueron formuladas durante el régimen de Pinochet" (Castro, Jaime Guzmán, ideas y política 12-13). En otros términos, arrojar luces de las ideas tras cada publicación escrita -sea esta académica, política o coyuntural, reflejada en los artículos, columnas o discursos de toda la vida de Guzmán- y su influjo en la realidad como arquitecto o "ideólogo" del proyecto de la Junta Militar, elemento que lo posiciona como un protagonista de interés para las actuales discusiones historiográficas y en otras disciplinas sociales.

Respecto de lo anterior, no son pocos los trabajos académicos que "[...] a partir de una relación directa con los escritos y apariciones públicas de Guzmán" han buscado "develar los fundamentos de su pensamiento" (Arqueros y Frontaura 10), entre ellos, y solo por dar algunos ejemplos, se encuentran $L a$ Constitución Liberal de Guzmán de Javier Silva Salas, La Historia de la UDI de Víctor Muñoz Tamayo o Jaime Guzmán, una democracia contrarrevolucionaria de Belén Moncada.

Mucha tinta se ha escrito sobre Jaime Guzmán, ${ }^{5}$ sin embargo, este texto entrega una mirada desde la archivística para aportar en la reconstrucción del pasado reciente, reflexionando en torno a la relevancia del acceso a la información gravitante para las discusiones fundamentales del período, y las aportaciones referente a lo teórico- que puede contener el revisar un archivo personal.

\section{ARCHIVOS PERSONALES DE INTERÉS CIUDADANO ¿PÚBLICOS O PRIVADOS?}

El libro ¿Qué es la Historia? de E. H. Carr parece ser preciso para comenzar a explicar esta visión indivisible entre la historiografía y la archivística. No a razón del contenido del texto propiamente tal, sino que un capítulo anexado al cuerpo principal que el paso del tiempo nos regalaría a los lectores.

R. W. Davies, historiador económico, entrega para las ediciones póstumas del libro citado un apartado donde menciona que Carr, con quien había escrito obras en conjunto, tenía pensado publicar una segunda edición ampliada de este 
texto que no alcanzó a terminar al momento de fallecer. Davies supo de esta nueva entrega gracias a que revisó el archivo personal del fenecido historiador y se percató de borradores, anotaciones y recortes que incluiría Carr en la nueva edición. Bastó con un análisis a un prólogo a medio terminar, además de sumergirse entre cajas, sobres y otros contenedores para componer un capítulo completo de lo que podría haber tratado el nuevo escrito del historiador fallecido. En definitiva, a partir de un archivo personal, se puede recomponer, ficcionalmente, también su quehacer. ${ }^{6}$ Ahora bien, tener acceso al archivo personal de E. H. Carr permitió toda esta elaboración, y es por eso que es relevante comprender las dimensiones que un archivo privado puede tener para el interés ciudadano.

Así lo comprendieron igualmente familiares y amigos de Jaime Guzmán, quienes donaron íntegramente los textos del exsenador a la fundación creada pocos meses después de su asesinato, con la misión de "juntar todos sus escritos, en oír y transcribir cientos y quizás miles de horas de cinta y videos [...] revisar publicaciones científicas, políticas y de actualidad; diarios y actas de sesiones; charlas, clases y conferencias. Después hay que ordenar, indexar y editar" (Rojas). La tarea descrita es la de recomponer el archivo -así como la incorporación de colecciones- lo más completo posible, con la obra del líder gremialista.

Entenderemos como archivo personal a aquel conjunto de documentos producido y/o almacenado por una persona física a lo largo de su vida, incluyendo todas sus funciones y actividades, independientes del soporte. Estos archivos se caracterizan por ser "heterogéneos, fragmentarios e incoherentes, formados en su gran mayoría por documentos sueltos" ("Los archivos personales"; Ríos 52; Gallego 47). Ciertamente, también refiere a la procedencia de la documentación, así lo consagra Marta Lucía Giraldo, cuando menciona que el archivo debe ser concebido "[...] como un todo orgánico, que incluye tanto el continente [hablando del repositorio] como el contenido" (33). Junto con lo anterior, como se trata de un archivo de una persona de connotación pública y fallecida, se puede establecer que es un archivo cerrado e histórico - por su ubicación en el ciclo de vida de los documentos- ya que "[...] se conservan los documentos seleccionados por su valor permanente, en condiciones que garanticen su integridad y transmisión a las generaciones futuras" (Cruz Mundet, Administración 28).

En otras palabras, un archivo es privado cuando la institución archivística o fondo pertenece a una entidad privada: organización, familia o persona. De esta manera, en un archivo privado puede haber documentos públicos sin contradecir

6 Referido a "De los archivos de E. H. Carr: notas preparatorias para una segunda edición de ¿Qué es la Historia?". 
su identidad, pues su definición apunta a la pertenencia del total documental y no de cada material de archivalía en particular (Tanodi y Tanodi 111; Duranti y Franks 267).

Con todo lo antes mencionado, en un primer momento en 1991, al revisar el archivo personal de Guzmán, “[...] se halló una serie de escritos claramente estructurados como parte de un libro en lo que, de acuerdo con un esquema hecho por el mismo autor, esbozaba lo que sería una futura publicación". Este libro que Guzmán dejó a medio terminar -al igual que Carr y su segunda versión de ¿Qué es la Historia?-, finalmente fue publicado póstumamente a un año del asesinato del exsenador bajo el título de Escritos personales (11). ${ }^{7}$

No es de extrañar que convivan en un archivo personal de un político, documentos de naturaleza privada, como cartas personales, y también documentos de naturaleza pública, como sus intervenciones como senador de la República. Revisar esa tensión entre lo público y lo privado en los documentos es necesario para hablar de archivos y, al ser este trabajo un estudio de caso, se inserta en el Archivo Jaime Guzmán E., cuya misión es la de almacenar, preservar y dar acceso al conjunto de documentos guarecidos por el exsenador hasta el momento de su deceso, es decir, comprende el fondo documental de Guzmán desde que era un niño hasta el material de archivalía producido poco antes de ser asesinado (1946-1991). A este respecto, la convivencia documental privada/pública de este fondo adquiere relevancia ante el debate del acceso a la información pues, en todo caso, los archivos personales no se piensan orgánicamente en una lógica de un espacio abierto, sino más bien restringidos. Cabe preguntarse entonces, ¿son los documentos personales de un personaje público también de interés público, y por ello, necesarios de abrir a acceso?

En 1984, cuando se discutía sobre una modificación a la ley de abusos de publicidad en Chile, Jaime Guzmán, como columnista periódico, publica una columna de opinión con sus consideraciones sobre lo público y lo privado que ayudan a arrojar luces sobre el problema planteado. Menciona en el escrito: "Nadie ignora en qué consiste la diferencia entre la vida privada y la vida pública. El problema es otro y reside en que -efectivamente- existen situaciones dudosas o zonas fronterizas donde resultará controvertible en cuál de los dos ámbitos nos encontramos". Para poder resolver esas zonas grises, Guzmán le atribuye de la inconclusa sinfonía no. 10 de Ludwig van Beethoven, obra que al morir el compositor "solo había escrito unas pocas notas, unos diagramas y algunos bocetos" (Hitos y artistas) y que luego fueron culminados por una inteligencia artificial que analizó el resto de la obra, dando posibles versiones de la inacabada partitura. 
esa responsabilidad al "papel insustituible que juegan al respecto la doctrina de los especialistas [...]" (Guzmán, Vida privada). Claro está que si bien se refería al respecto del área jurídica, en lo que compete a la archivística se debe aplicar la misma premisa, es decir, esta situación debe ser evaluada por los encargados del archivo en cuestión, los profesionales del área, logrando discernir entre los documentos que desde su creación se pensaron para ser públicos o privados, siguiendo el criterio de las investigaciones de los encargados de los archivos.

Otro grupo [de investigadores] se deberá encargar de entrar gradualmente en la intimidad de su vida [la de Jaime Guzmán]... Estos mismos investigadores deberán acceder a su archivo personal, a sus papeles más preciados, que son parte importante de su historia individual y de la trayectoria de nuestra patria en el último cuarto de siglo (Rojas).

Así, a los documentos privados -que refiere al documento producido por un ente privado, además de aquellos documentos emitidos por entidades públicas que están asociadas por su naturaleza con el derecho privado y se asimilan en sus formas a los creados por privados (Duranti 84; Torres 144)- que son de interés por su significancia, se puede y debe asegurar el libre acceso a estos o su contenido (la información de interés) para el ciudadano crítico y el investigador, según se requiera. Esta perspectiva, que comparten académicos como José Manuel Castro, permitiría que:

[...] en las próximas décadas este [el Archivo Jaime Guzmán] y otros archivos políticos [...] queden disponibles de manera íntegra, ofreciendo material valioso para investigaciones históricas y políticas que buscan comprender el rol jugado por estos líderes políticos en nuestro agitado y todavía controvertido pasado reciente (Archivo).

Cabe aclarar en este punto que el archivero no oculta información, no podría ni ética ni disciplinariamente, sino que logra emular al archivo institucional que comprende los residuos documentales propios de sus actividades. Es por ello que los documentos que son de interés ciudadano deben ser accesibles $y$, por consiguiente, el archivero debe velar porque así sea. No obstante, el orden jurídico también complejiza el panorama del acceso a los archivos personales, ¿qué ocurre con los derechos, por ejemplo, al respeto de la vida privada, a la protección de datos personales o a la inviolabilidad de los documentos privados? 
Ante estas preguntas es que el consentimiento es clave, y por ello los responsables de los archivos personales -sea la propia persona o cual sea la institución que lo administre, estando vivo o muerto el productor- deben discernir para hacer público aquello que es menester.

Por la naturaleza de los documentos referidos, debemos abordar la dimensión del derecho privado bajo el cual, según el adagio jurídico, está permitido hacer todo aquello que la ley no prohíbe, mientras que en derecho público solo se puede hacer lo que la ley expresamente mandata. Frente a esto, los archivos privados deberán procurar no pasar a llevar con su información a terceras personas que no han consentido la publicación de dicho contenido, así como considerar el derecho de los propietarios a la libre utilización de un bien personal, por lo que la concientización respecto del acceso se vuelve crucial para resolver los obstáculos expuestos, de manera tal que puedan consentir el acceso.

\section{ACCESO}

En la fricción entre lo público y lo privado, es necesario reconocer el rol que los archivos han jugado en una sociedad que, hasta la implementación de la ley de Transparencia de la Función Pública y de Acceso a la Información de la Administración del Estado (Ley 20.285), no dimensionaba su importancia para la ciudadanía. La conexión indisoluble entre la transparencia -tanto histórica como del Estado-y la gestión de los archivos, es comprobada por la historia misma de los depósitos documentales. Desde los primeros Estados consolidados existe la creación de espacios para resguardar los documentos de interés nacional, como los acuerdos y pactos - políticos y territoriales, que podrían marcar la diferencia a la hora de ejercer soberanía en un espacio determinado- o las obras de algún gobernante (Mendo 114). Estos documentos pasan por la criticidad histórica y la opinión ciudadana, esto es, los archivos aportan al control de la gestión estatal. Por tanto, el Estado y sus ciudadanos se benefician de la existencia de las instituciones archivísticas.

Junto con lo anterior, el conocimiento de nuestra historia es relevante en la conformación de la identidad nacional, que también se consigue a escalas menores. Así, la creación de literatura referida a la historia del país, la región o incluso a niveles más locales, como las comunas o barrios, requiere de las fuentes que sustenten el relato que los investigadores construyen. Es por ello que los archivos, al ser los receptores de esas fuentes que dan sustento a la historiografía, son indispensables para las sociedades. 
Basta agregar a la lista que, así como a nivel macro el Estado necesita de un archivo, también lo urgen los cuerpos intermedios de la sociedad y para labores similares. La vitalidad de los archivos privados (sea de organizaciones, familias o archivos personales) recae en la posibilidad de reencontrar y rememorar la historia particular, así como de conocer y controlar las gestiones propias, resolver problemas a través de documentación y permitir la transparencia con los grupos de interés. En síntesis, los archivos son instituciones necesarias para el desarrollo de los Estados modernos, sus instituciones y cualquier agrupación, incluyendo a cada persona en particular.

Ejemplo de esta intención de poner a disposición archivos privados por el interés que genera en la ciudadanía, es que el actual poseedor de parte del acervo personal del nobel de literatura Pablo Neruda, Sergio Vivanco, subastará las piezas documentales con la condición de que "el lote no se disperse y que el comprador -sea una institución pública o un particular-asegure su conservación y exhibición". Esta consciencia del respeto al principio de orden original se suma a una comprensión de la necesidad de acceso: "Me daba pena tenerla en la casa, son cosas que tienen que estar en un sitio donde se puedan compartir con admiradores y estudiosos de su obra" comenta en la misma nota el poseedor del conjunto documental ("Subastarán el archivo").

El acceso se define en la literatura como el reconocimiento de la institución archivística a un usuario con el permiso o privilegio para ver o utilizar un documento o grupo de estos. El usuario con acceso puede ser una persona, tecnología y/o procedimiento que necesite los documentos de archivo para un propósito específico. Este acceso se debe garantizar que sea lo más amplio posible (Duranti y Franks 1; ICA 3).

A consecuencia de lo anterior, el legado histórico que resguarda la Fundación Jaime Guzmán referente al exsenador ha sido un importante aporte a diferentes textos académicos, políticos e historiográficos, dejando a la ciudadanía conocer su obra, su vida y su pensamiento mediante procedimiento de solicitud. Para aportar a la extensión referente al acceso, la FJG preparó la difusión de una versión digital del archivo, cuya habilitación pública se realizó el 5 de mayo de 2019 ("Fundación publica archivo"), a través de una plataforma de Access to Memory (AtoM) ${ }^{8}$ y fue pensada para que "contribuya a la comprensión de su proyecto humano y social [de Jaime Guzmán], e impulse la investigación Archivos, como la institucional con normativa ISIAH (del inglés original International Standard for Institutions with Archival Holdings) o el material de archivalía con la norma ISAD-G (sigla de General International Standard Archival Description). 
de nuevas generaciones para informar fidedignamente los fundamentos de su obra pública que le valieron convertirse en un ejemplo de servidor público" (Jaraquemada).

Así, se facilita el acceso reduciendo las solicitudes presenciales, ya que la documentación está dispuesta de manera gratuita a través de un software pensado archivísticamente (Téllez 211-212). De esta manera, muchas de las limitantes de acceso se resuelven, tales como mantener el estado material de los documentos por manipulación, la generación de multiplicidad de copias de un documento por cada consultante o los límites horarios o de personal (Duchein 7).

De lo anterior se extrae que "La informática [...] se ha convertido en elemento esencial para el desempeño de los procesos archivísticos" (Giraldo 41), por tanto, la integración de las tecnologías de la información y la comunicación (TIC) en el trabajo archivístico es una posibilidad no solo en la automatización del tratamiento de los documentos -clasificación, ordenación, descripción y conservación-, sino especialmente en el apoyo al acceso, donde "las nuevas tecnologías permiten construir una nueva modalidad de lectura, en la que el lector puede abandonar el lugar de receptor y acceder a un rol más activo" (Pittaluga 204).

\section{CONCLUSIONES}

La historiografía tiene desafíos a la hora de acceder a las fuentes que respaldan los trabajos disciplinares, y si bien cada período de la humanidad estudiado tiene sus propias complejidades, ciertamente la historia de Chile desde mediados del siglo XX cuenta con barreras en su estudio, en primer lugar, por la desconfianza en las fuentes tradicionales, pero además por la cercanía de los hechos, que abordan dimensiones emocionales y políticas a las que, inevitablemente, suelen marchar estas discusiones. Reconstruir ese pretérito ha sido prolífico para la pluma historiográfica, por ello es necesario que el acceso a los fondos documentales de interés ciudadano pueda y deba promoverse, de manera de sumar a los privados en este proceso.

Las transformaciones que se han dado en los intereses de los investigadores hacen que cada vez más los papeles y documentos personales sean una fuente inagotable de recursos para futuras investigaciones. Es importante también que tanto los archivistas como los encargados de elaborar las políticas públicas concienticen a la población de la importancia de conservar la documentación 
no sólo de personalidades reconocidas sino también de la "gente común", ya que cada archivo representa una parte diferente de la realidad en un momento histórico determinado (Bossié 4).

Aún más si consideramos que "los archivos personales contienen información única e irremplazable, [que] son fuentes de incalculable valor para la investigación y reconstrucción de los procesos históricos de los pueblos" (Ríos 52). Dicho de otro modo, hoy cuando la historiografía ha buscado nuevos elementos a la hora de considerar fuentes, como la oralidad (Pinto 95) -solo por dar un ejemplo-, los archivos personales son una posibilidad que la disciplina archivística, en su vínculo inherente con la historia, propone para abordar las dificultades de escribir el pasado reciente. Como menciona Michel de Certeau: "la transformación de la 'archivística' es el punto de partida, la condición de una nueva historia" (88), por tanto, estas nuevas escuelas historiográficas, críticas de sus predecesoras de antaño, deben comprender el papel de los archivos como parte de su quehacer. En otros términos, "La archivación no es meramente una actividad que colabora en lo que luego será la escritura de la historia, no es sólo un terreno sobre el cual otra actividad -la historiografía- actuaría. El arte del archivo es escritura historiográfica" (Pittaluga 204).

El escritor argentino Jorge Luis Borges, en su cuento Funes el memorioso de 1942, relata la historia de Ireneo Funes, un hombre que luego de un accidente es incapaz de olvidar: "Mi memoria, señor, es como vaciadero de basuras" sentencia en el texto el personaje, haciendo alusión a su asombrosa habilidad:

Nosotros, de un vistazo, percibimos tres copas en una mesa; Funes, todos los vástagos y racimos y frutos que comprende una parra. Sabía las formas de las nubes australes del amanecer del treinta de abril de mil ochocientos ochenta y dos y podía compararlas en el recuerdo con las vetas de un libro en pasta española que sólo había mirado una vez y con las líneas de la espuma que un remo levantó en el Río Negro la víspera de la acción del Quebracho. Esos recuerdos no eran simples; cada imagen visual estaba ligada a sensaciones musculares, térmicas, etc. Podía reconstruir todos los sueños, todos los entresueños. Dos o tres veces había reconstruido un día entero; no había dudado nunca, pero cada reconstrucción había requerido un día entero. Me dijo: Más recuerdos tengo yo solo que los que habrán tenido todos los hombres desde que el mundo es mundo. (Borges 131) 
Si bien este cuento ha tenido variadas interpretaciones, como que se trata del insomnio, de la lingüística o sobre la historia, lo cierto es que bien podría tratar -como lo señala Emma de Ramón- sobre los archivos: grandes depósitos que podemos llenar de cientos de documentos, mal entendidos como el "vaciadero de basuras" en el ciclo de vida de los documentos, cuya información hace a su vez de recuerdos, pero recuerdos sin procesar, porque Ireneo Funes no procesa, no piensa, solo almacena recuerdos. Esto último expresado por el narrador del cuento: "Sospecho, sin embargo, que [Funes] no era muy capaz de pensar. Pensar es olvidar diferencias, es generalizar, abstraer. En el abarrotado mundo de Funes no había sino detalles, casi inmediatos" (Borges 134).

La reflexión a la que llega de Ramón luego de su lectura de Funes, es que "no somos [los archiveros] simplemente unos cosechadores de papeles. Nosotros somos gente que piensa y que construye, en el fondo, series que dan cuenta de memoria. O sea, la memoria no es simplemente sacar una especie de copia de todo lo que nos rodea y tener todos los papeles del mundo, sino, justamente, seleccionarlo, y ver qué de eso es lo que realmente tiene o no valor, y esa es la gracia de nuestra profesión". Lo que se plantea aquí es la capacidad de selección que tienen los archiveros para valorizar la documentación, de modo tal -en uno de los usos de esa labor profesional- que pueden determinar la documentación privada que se permite el acceso al público, y de este modo, asegurar el uso de las fuentes relevantes y de interés para la ciudadanía.

La selección es fundamental disciplinalmente, no solo evitando que colapsen por espacios los depósitos en que los documentos son almacenados, sino que además porque permite la recuperación de aquello que es útil para las diversas funciones que los documentos de archivo tienen: las pruebas judiciales o legales, o las huellas históricas.

Los archivos, como mencionaba De Certeau, ya no eran grandes depósitos donde los papeles eran solo resguardados, su rol frente a este panorama es que permite que la accesibilidad a la documentación sea la médula de la disciplina archivística, en otros términos, "Es el uso de los documentos por parte de un conjunto de personas lo que hace que un depósito de documentos se transforme en un archivo, por lo que, en ausencia de este uso, el acto de preservar se vuelve inútil" (Andaur 235). ${ }^{9}$

9 Si bien ha habido etapas en el pasado donde los archivos eran lugares estrechamente abiertos únicamente al gobierno y eruditos, la necesidad de los archivos para la función de una ciudadanía crítica y una sociedad activa de información, posicionan hoy al archivo como un lugar necesariamente accesible (Vivas Moreno; Duchein 2). 
Si consideramos que "Los acervos documentales, por su parte, corresponden a huellas de las personas, que nos permiten entrar en los pequeños instantes de su cotidianeidad" (AN 7), tenemos, por tanto, un vestigio del pasado que no solo nos permite comprender las ideas, en cuanto espacio de libre disposición de ellas, de una persona en particular, sino que además de los aportes a la reconstrucción de momentos más específicos de la temporalidad, en una escala mucho menor.

Para acceder a esta documentación, el trabajo del archivero es esencial, discriminando la documentación que por su contenido e interés debe cruzar desde la privacidad propia de un archivo personal, a su publicación (acceso). En un trabajo que permita a los usuarios interesados en rescatar estos elementos para la agencia historiográfica, pudiendo explicar de mejor manera-como lo es la forma de pensar de un protagonista del momento, o alcanzando mayores detalles de lo ocurrido un día que un historiador concluyó "histórico", solo por dar ejemplosel pretérito estudiado. Saber escudriñar, entonces, en estos espacios es una vital necesidad que, junto con volver a darle importancia a los documentos de archivo como fuente, también realza el trabajo y utilidad de cientos, miles o incluso millones de estos depósitos que hoy cada uno de nosotros conforma, además de las diferentes instituciones, empresas o grupos, que juntas entraman nuestro tejido social y podrán, por su propia naturaleza ligada al quehacer de cada quien, reconstruir la historia de todos nosotros, incluyendo, como es el propósito de este artículo, el pasado reciente de Chile.

Esta revisión teórica pretende expresar los beneficios de la integración de los archivos personales a las voces que la historiografía puede utilizar en su desarrollo disciplinar, y con ello permitir que el juicio respecto de las personas cuyos archivos se revisan, sean un punto aparte de dicho análisis.

Desde la historiografía, y tras casi treinta años del asesinato de Jaime Guzmán, se hace necesario conocer su pensamiento y acción. Lo primero, a través de la lectura directa de sus escritos, artículos de prensa, cartas, discursos y cientos de documentos disponibles. Lo segundo, mediante una investigación biográfica que aspire a comprender y explicar al hombre en su tiempo. (Castro, Jaime Guzmán en la historia)

Frente a esta disyuntiva ante personas relevantes, pero también controversiales, es que el llamado debiese conducirnos a colocarlos en ese espacio del desarrollo del devenir que les corresponde como protagonistas para explicar los fenómenos del presente, y no como una nueva trinchera ideológica, 
recordando como principio que "[...] el archivo sirve tanto a la historia descriptiva como a la problemática, y tanto a una ideología conservadora como a una ideología revolucionaria" (Cassese 54).

\section{REFERENCIAS BIBLIOGRÁFICAS}

\section{Archivos}

Archivo Fundación Jaime Guzmán E., Santiago de Chile.

\section{Bibliografía}

Andaur, Gabriela. "Experiencias y satisfacción de usuarios en el Acceso al Archivo: Estudio de caso en el Archivo Nacional Histórico de Chile”. Actas del XII Congreso de Archivología del Mercosur, Tomo I Acceso a la Información, Redes, 2017, pp. 234 - 248

Archivo Nacional [AN]. Guía docente: talleres de educación en archivos, memoria y ciudadanía, Gobierno de Chile, 2017.

Arqueros, Claudio y Carlos Frontaura. Persona, Sociedad y Estado en Jaime Guzmán. A 30 años de la caída del Muro de Berlín. Editorial JGE, segunda edición ampliada, 2019.

Borges, Jorge Luis. "Funes el memorioso". Ficciones, Debolsillo, 2016.

Bossié, Florencia. "Archivos personales: su tipo particular de organización y tratamiento documental". 3er Congreso Internacional CELEHIS de literatura. Abril de 2008. http://www.memoria.fahce.unlp.edu.ar/trab eventos/ev.3577/ev.3577.pdf

Carr, Edward H. ¿Qué es la Historia?. Ed. Ariel, 2017.

Cassese, Leopoldo. Teoría e metodología, scritti editi e inediti di paleografia, diplomática, archivistica e biblioteconomia, editor Attilio Mauro Caproni, Laveglia, 1980.

Castro, José Manuel. "Jaime Guzmán en la historia de Chile", Revista Realidad, abril 2020, p. 6. https://online.flippingbook.com/view/661648/

---. Jaime Guzmán, ideas y política 1946-1973: corporativismo, gremialismo, anticomunismo, vol. 1, Centro de Estudios Bicentenario, 2016.

---. “Archivo Jaime Guzmán”, El Mercurio, 06 de mayo de 2019, p. A2

Collingwood, R. G. Idea de la historia, Fondo de Cultura Económica, edición revisada, 2014 
Cook, Terry. "Panoramas del pasado: archiveros, historiadores y combate por la memoria", Tabula, no. 13, año 2010, pp. 153-166.

Cruz Mundet, José Ramón. Diccionario de Archivística. Alianza Editorial, 2011. ---, director. Administración de documentos y archivos. Textos fundamentales. CAA, 2011.

De Certeau, Michel. La escritura de la historia. Universidad iberoamericana, 2006.

De Ramón, Emma. "Charla inaugural: Memoria y Comunidades, rol y dimensión de los archivos como fuente de memoria colectiva, de identidad y pertenencia", Escuela Nacional de Archivos, Archivo Nacional, 6 de enero de 2020. https://www.youtube.com/watch?v=vC1F3Q_yoNc

Duchein, Michel. Los obstáculos que se oponen al acceso, a la utilización y a la transferencia de la información conservada en los archivos: un estudio del RAMP. UNESCO, 1983. https://unesdoc.unesco.org/ark:/48223/ pf0000057672_spa

Duranti, Luciana y Patricia Franks, editoras. Encyclopedia of Archival Sciences. Rowman \& Littlefield Publishers, 2015.

Duranti, Luciana. Diplomática: usos nuevos para una antigua ciencia. S\&C Ediciones, 1996

Falaize, Benoît. "L'enseigement des sujets controversés dans l'école française: les nouveaux fondements de l'histoire scoilaire en France?". Tempo \& Argumento, vol. 6, no. 11, 2014, pp. 193-223. http://dx.doi.org/10.5965/2175180306112014193

"Fundación Jaime Guzmán publica archivo del senador". El Mercurio, 5 de mayo de 2019, p. C4.

Gallego, Olga. Manual de archivos familiares. ANABAD, 1993.

Ginzburg, Carlo. El Hilo y las Huellas. Lo verdadero, lo falso y lo ficticio. Fondo de Cultura Económica, 2010.

Giraldo Lopera, Marta Lucía. "Archivística: Fundamentación teórica y tradición formativa". Revista Interamericana de bibliotecología, vol. 32, no. 1, 2009, pp. 31-45.

Guzmán, Jaime. "Dos 11 de septiembre históricos". La Segunda, 10 de septiembre de 1982.

---. Escritos personales. Editorial JGE, 5ta edición, 2011.

---. "Vida privada y vida pública". Ercilla, 6 de junio de 1984.

International Council on Archives [ICA]. Código de ética profesional, 1996.

Jaraquemada, Jorge. "Bienvenida a Archivo Jaime Guzmán”. Archivo Jaime Guzmán, rescatado el 6 de septiembre 2019. https://archivojaimeguzman. cl/index.php/ 
López, Carlos. "La construcción del relato histórico: fuentes, narrativa e imaginación”. Revista La Universidad, no. 21, 2013, pp. 159-169.

"Los archivos personales son fuente para la investigación". Universidad de Montevideo, 15 de abril de 2018. http://um.edu.uy/noticias/64709-losarchivos-personales-son-fuentes-para-la-investigacion/

"Los hitos y artistas para conmemorar en 2020". El Mercurio, 2 de enero de 202, p. A9.

Mayol, Paula et al. La permanente presencia de un hombre llamado Jaime. Tesis de Grado de Licenciatura en Comunicación Social, Universidad Diego Portales, 2004.

Mendo, Concepción. "El largo camino de la archivística: de práctica a ciencia". Signo: Revista de Historia de la Cultura Escrita, 1995, pp. 113-132.

Moncada, Belén. Jaime Guzmán. Una democracia contrarrevolucionaria: El político de 1964 a 1980. RIL editores, 2006.

Muñoz Tamayo, Víctor. La historia de la UDI: generaciones y cultura política (1973-2013). E. Universidad Alberto Hurtado, 2016.

Pinto Vallejos, Julio. La historiografía chilena durante el siglo XX. Cien años de propuestas y combates. Ed. América en Movimiento, 2016.

Pittaluga, Roberto. "Notas a la relación entre archivos e historia". Anuario Políticas de la Memoria, no. 6/7, verano de 2006/2007. https://studylib.es/ doc/8437271/pol\%C3\%ADticas-de-la-memoria-6-7-verano-2006-2007

Ríos, Patricia. "La importancia de la organización y conservación de un archivo personal". Revista Universidad de Sonora, 2008. http://www. revistauniversidad.uson.mx/revistas/23-11.pdf

Rojas, Gonzalo. “Tres proyectos para Jaime Guzmán”. Ercilla, 10 de abril de 1991. Rosell León, Yorbelis. "La descripción como parte del tratamiento de los archivos personales en el siglo XXI: en busca de nuevas alternativas". ACIMED, vol. 14, no. 5, octubre de 2006.

Silva Salas, Javier. La constitución liberal de Guzmán. Chile 1973-1980. Ed. Universidad San Sebastián y Ciudadano Austral, 2017.

"Subastarán el archivo privado más importante de Pablo Neruda". El Mercurio, 28 de febrero de 2020, p. A7.

Tanodi, Aurelio y Branka Tanodi. Manual de Archivología Hispanoamericana. Teoría y principio. Ed. Brujas, 2010.

Téllez Rodero, Núria. "Gestión documental y software libre en el Archivo Histórico del Centro Excursionista de Cataluña (AHCEC). La descripción de sus fondos documentales a través de la implantación del programa ICA-ATOM". 7.as Jornadas Archivando, recopiladores Javier González et al., 2014, pp. 208-215 
Torres, Natalia, compiladora. Hacia una política integral de gestión de la información pública: todo lo que necesitas saber sobre los archivos. Universidad de Palermo, 2014.

Vivas Moreno, Agustín. Breve historia cultural de la archivística. Abecedario, 2013.

White, Hayden. Ficción histórica, historia ficcional y realidad histórica. Ed. Prometeo, 2010. 